\title{
Maintenance of Municipality Infrastructure: A Case Study on Service Delivery in Limpopo Province at South Africa
}

\author{
Mogooe Malokane Emily, Goodwell Muyengwa \\ Department of Mechanical and Industrial Technology, Faculty of Engineering and the Built Environment, University of Johannesburg, \\ Johannesburg, Gauteng, South Africa \\ Email: malokaneemily@gmail.com,gmuyengwa@uj.ac.za
}

How to cite this paper: Emily, M.M. and Muyengwa, G. (2021) Maintenance of Municipality Infrastructure: A Case Study on Service Delivery in Limpopo Province at South Africa. American Journal of Operations Research, 11, 309-323.

https://doi.org/10.4236/ajor.2021.116019

Received: June 17, 2021

Accepted: October 30, 2021

Published: November 3, 2021

Copyright $\odot 2021$ by author(s) and Scientific Research Publishing Inc. This work is licensed under the Creative Commons Attribution International License (CC BY 4.0).

http://creativecommons.org/licenses/by/4.0/

\begin{abstract}
Purpose: An element of poor service delivery concerns the quality of management on the maintenance of services like water, electricity, roads, schools and clinics. This is a relevant and topical issue for research because of the current situation regarding these provisions in South Africa. This research took place in a Municipality situated in Limpopo Province, South Africa. It is the responsibility of municipalities to ensure that they fulfil their constitutional obligations in the delivery of maintainable, operative and well-organised municipal services through the maintenance of infrastructure. As this country has been subjected to a large number of service delivery complaints, this has led to the motivation of this study. The purpose of this study is to analyse maintenance on municipal infrastructure and service delivery in a local municipality, in particular focusing on the water supply. This research study is aimed at analysing how local municipality conducts its maintenance of municipal infrastructure, seeking to understand the challenge of maintenance on service provided to the communities. Design/Methodology/Approach: To achieve the success of this research, both qualitative and quantitative methods were adopted. A survey questionnaire and structured interview questions were conducted with communities and employees in a municipality in Limpopo Province. Findings: The results of the study revealed that residents are facing water difficulties due to a lack of maintenance and absence of water supply. People are fetching water from the rivers in the nearby community, water which unfortunately is not purified. Furthermore, people have experienced this poor maintenance and service delivery for years, negatively impacting on the community's standard of living. Originality/Value: The original contribution of this work was to analyse the types of maintenance being used in local municipalities and how it will benefit the communities. To the best of the
\end{abstract}


authors' understanding, there are no studies that have been conducted in South Africa regarding the impact of maintenance on municipal infrastructure, and this paper aims to fill this gap.

\section{Keywords}

Maintenance, Infrastructure, Service Delivery and Municipality

\section{Introduction}

The South African Constitution stipulates that municipalities have the mandate to ensure an uninterrupted supply of basic services such as water, electricity, roads, schools and clinics to all its communities. The Municipality has been defined as the institution of government that is tasked with the improvement and provision of services to its people. Even though the municipalities have been constitutionally instructed to provide sustainable and effective services, this is not necessarily an easy task. Literature suggests that improved maintenance on municipal infrastructure will increase service delivery through the reduction of the breakdown of equipment and better maintenance strategies. It is important to not only focus on the services delivered, but also to consider the various difficulties faced by the municipalities in their efforts to attain these objectives. Therefore, a significant study of service provision and maintenance by the municipalities to the communities was conducted. The idea behind the study was to analyse the methods used by a particular municipality for the maintenance of municipal infrastructure, the service provided to the community, and furthermore, based on the findings, to propose improvement strategies. The problem of service delivery has affected countless people in South Africa. Regardless of the country's transition into democracy, many places continue to be destitute, deprived, and inequality persists in too many areas of South African. The vast majority of the residents in Limpopo Province are complaining of polluted and unusable water from nearby rivers shared with farm animals, because of consistent shortages in unreliable water supply and poor management systems. The few households who can afford, depend on water provided by private suppliers who operate under unhygienic conditions, or pay a ridiculous amount of money to boring/drilling companies to obtain drinkable water. This is difficult for the poor majority of people who are pensioners and unemployed who solely depend on insufficient government pension funds for their basic living needs.

\subsection{Study Area}

Limpopo is well known for scarcity of rain and it is predominately a dry area hence it suffers water shortages. The study took place in a municipality in Limpopo province. Figure 1 represents the location map of the study area and Table 1 represents the growth of the studied Municipality population. Similar to rural municipalities in the Republic of South Africa, some of the municipalities 
Table 1. Population growth.

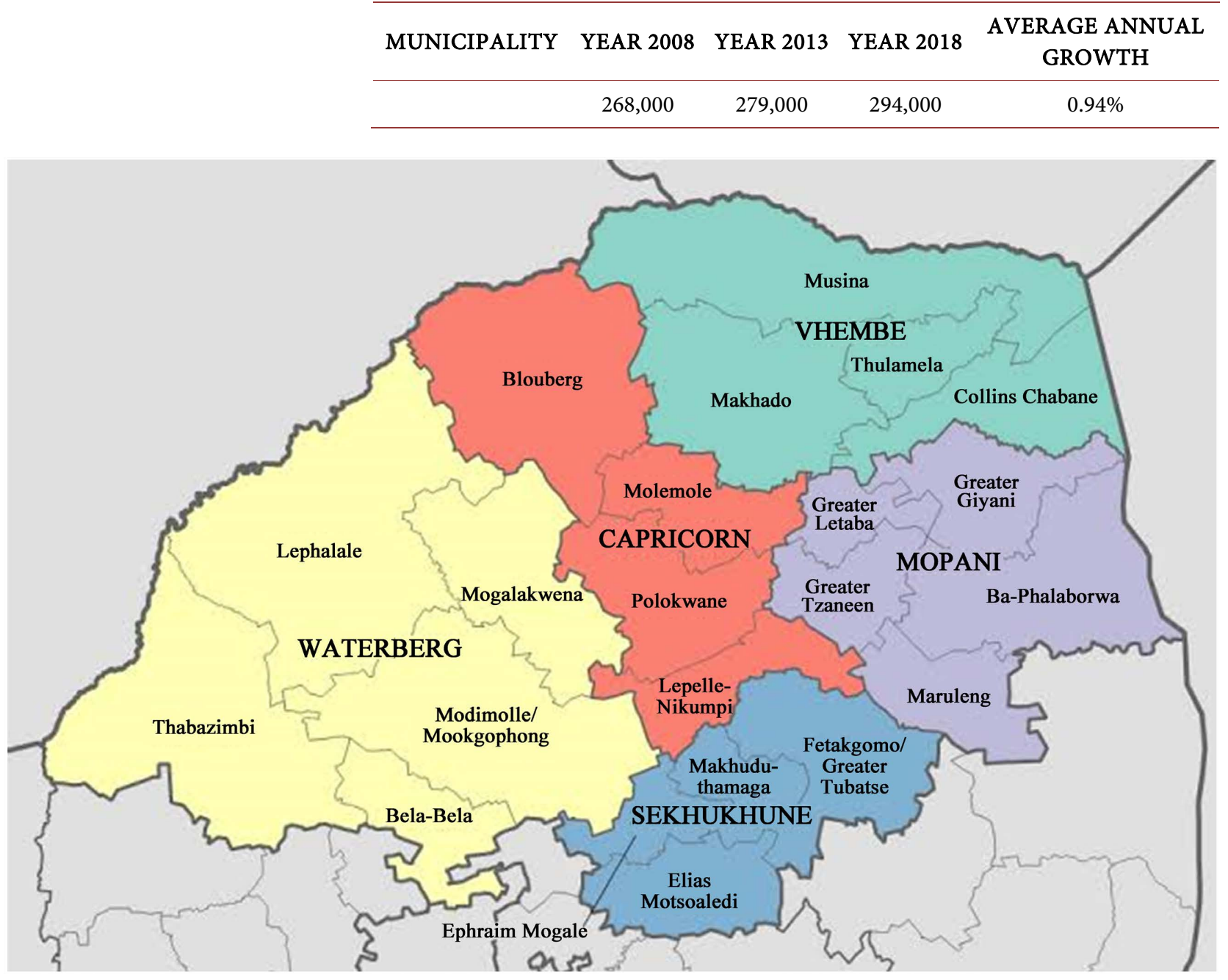

Figure 1. The location map of the study area (Limpopo Province).

in Limpopo province are categorised by an incapacitated economic base, poor infrastructure, major service delivery bottlenecks, distributed human settlements and high poverty levels.

The research will answer these questions:

Research question 1: What is the nature of maintenance implemented by municipalities? From an economic development point of view, infrastructure maintenance lowers the cost of production and consumption, and makes it easier for participants in the economy to enter into profitable transactions. The purpose of this question was to find out the efficiency of maintenance infrastructure that helps with the progression of service delivery and the performance results.

Research question 2: What maintenance management strategies can be recommended to the municipalities? There are four maintenance strategies namely: Preventive maintenance, Corrective maintenance, Risk-based maintenance and Condition-based maintenance. The researchers' aim was to analyse which main- 
tenance strategies were the municipality practising, can be used collaboratively, or independently. From the results of the study the researchers would then recommend better maintenance strategies.

Research question 3: What are the challenges to and enablers of successful management and implementation of maintenance? The purpose of this question was to find the challenges to successful management and implementation of maintenance. The researchers sought to establish these challenges through interviewing municipality employees and the residents.

Research question 4: What are the risks of poor maintenance on municipality infrastructure? Effectively functioning infrastructure is critical if the country as well as each community is to achieve any kind of economic recovery. Smooth running infrastructure programmes provide economic opportunities and act as a facilitator for generating economic growth and eventually paving the way for much needed job creation. Public properties are a foundation of a country's economic development. Preserving infrastructure in good condition is critical as equipment deterioration occurs with time and continuous use. The goal of maintenance is to safeguard an asset. This includes minor repairs (routine maintenance) and improvements (capital maintenance) to eliminate the cause of defects and to avoid excessive repetitions. The goal of this question was to identify the risks that municipalities are facing for the poor maintenance of their infrastructure.

Research question 5: How can municipalities improve maintenance management? The purpose of this question was to find ways/ process and procedures that can help municipalities to improve their maintenance management. Maintenance is usually a high labour-intensive work, and there are prospects that contribute to it.

\subsection{Municipalities}

The municipality is an administrative feature of the Constitution of the Republic of South Africa 1996, which was established by national and regional regulations to which the municipality is subordinate but has corporate status and powers of self-government or authority [1]. Municipalities are the most important government agencies answerable to the people for providing essential services and nurturing growth in the communities they administer [2]. This research will examine, as indicated from the above details, the degree to which the municipality meets its service delivery requirements. Good maintenance of municipal infrastructure can eradicate poverty and bolster economic development, with a well-functioning infrastructure and national assets. [3] Adequate infrastructure is a pillar of development, an important part of a supportive environment for investment and livelihoods, promoting economic growth, reducing poverty, and enhancing the delivery of health and other services. The country suffers a lack of infrastructure in rural areas where a large population of the inhabitants reside and work [4]. The Constitution of South Africa 1996 states that municipalities 
have accountability to guarantee that services are offered to the residents to meet their basic needs. Basic services are the main building blocks for improving the worth of people's lives; the suitable supply of clean water, electricity, hospitals, adequate roads and education are essential for life, wellbeing and human dignity [2]. Local government municipalities are the sphere of government closest to residents; members are elected by the people to serve, and are in control of the efficient provision of service, according to the Constitution of the Republic of South Africa 1996. Municipalities are the most successful level of government to achieve these goals and local economic development, since they are better placed to know what society wants, and they live within these communities [5]. The local government's proximity to neighbourhoods means that it is strategically placed to fulfil its mandate of supplying the public with basic needs as a first step towards community growth. Local governments are required to create alliances with their communities to provide services in a sustainable manner as part of their developmental role [6]. In reality, communities better understand their needs than public officials. The Constitution of the Republic of South Africa 1996 authorises municipalities to provide services in a justifiable manner and to provide facilities to municipal administrations: impartially, equally, equitably and without prejudice [7].

[8] Bathopele is a principle laid down in the Bathopele Republic of South Africa to improve citizen involvement for enhanced service delivery in South Africa in the emerging local governments: DPSA 2003. These principles are consistent with the constitutional values of nurturing and upholding high standards of professional ethics effectively and proficiently for utilising resources, responding to people's needs and holding public administration accountable [9]. In addition, the Municipal System Act 2000 requires municipalities to comply with the requirements of the Constitution by meeting the basic needs of the population, by encouraging resident development, and by guaranteeing that all local residents have at least access to the minimum level of basic municipal services [10].

\subsection{Service Delivery of Water}

Several nations face situations of water supplies inadequate to meet even the basic needs of people [11]. Even so, water is vital to human life, like air. All that we do in this world needs water, because without water there is no proper life. The Water Resources Act of 1997 (Act 108 of 1997) states that everyone is entitled to access a basic clean water sources. Water scarcity is a substantial development problem in Limpopo Province, limiting both economic and social activities in the area [12]. Moreover, the manifestation of climate variability is another problematic issue [2]. In addition, other issues including inadequate and variable rainfall, unequal water supply management and the absence of drinking water, bulk water and irrigation facilities, are further factors rendering it impossible for rural villages to distribute water as expected [13]. Ensuring rural water security 
has become a major challenge for sustainable development due to a growing population, deteriorating water conditions and climate change impacts [14]. This calls for new, imaginative approaches that are ecologically sustainable and cost-effective [15], and also the need to make sure that the municipal water infrastructure is well maintained [8].

The public-sector infrastructure report of the 2019 budget review details that from 1998/99 and 2017/18, the public sector spent R3 trillion on infrastructure [16]. Spending grew in 1998/99 from R48.8 billion to R236.2 billion in 2017/18 [16]. In actual terms, capital investment has risen by a yearly average of $4.3 \%$. State-owned companies have invested R1.3 trillion in infrastructure over the course of this time [16]. For the 2019 budget review, municipalities and provincial departments spent R612.8 billion and R705.2 billion on the construction of schools, hospitals, clinics and other community-related facilities, respectively (refer to Figure 2, the National Treasury Source from 1998/9 to 2017/18) [16]. Public-sector capital investment averaged $5.9 \%$ as a share of the gross domestic product (GDP). Both government agencies and public enterprises have significantly expanded their spending in economic infrastructure over the past years, although social infrastructure costs, including schools, hospitals and sanitation, has risen at a slower pace. Slower growth in social infrastructure spending is the outcome of financial capital pressure, including the increase in the government's wage bill and new policy commitments from the 2019 budget reform review [16]. [17] despite the importance of water to livelihoods, over 783 million of the world's population has no access to clean water. Challenges encountered concerning the delivery of water to the public include but not limited to miscommunication between different water agencies, limited resources, leakages in official spending and lack of monitoring progress of different water projects, [14]. A government body's delivery of a service can be considered as a process of producing value for a number of different stakeholders, [12] furthermore, the stakeholders will participate at different points in the value-network and therefore

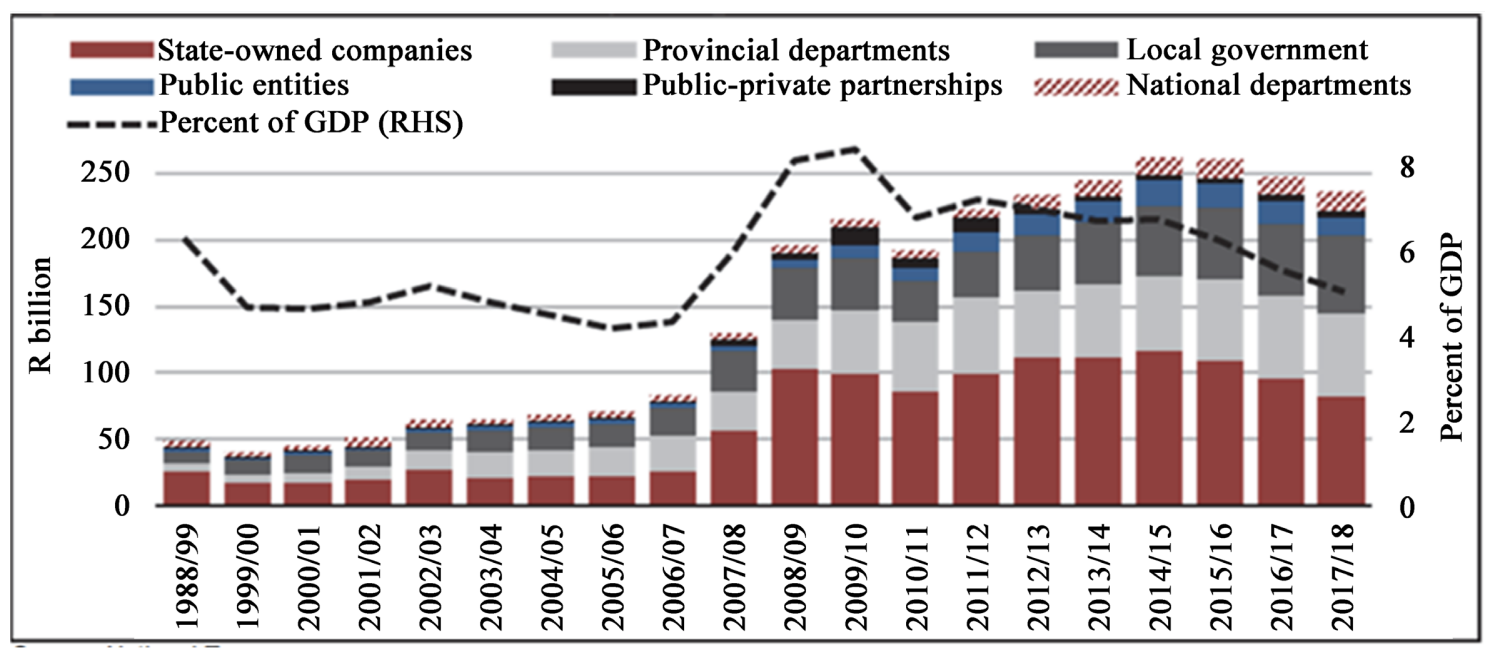

Figure 2. The source national treasury, public-sector infrastructure spending. 
will interact with different government systems [12].

\subsection{Maintenance}

[18] defines maintenance as the actions intended for preserving something in or returning it to the physical state deemed appropriate to fulfil production objective, while the maintenance concept is a set of different types of maintenance policies and actions and the overall planned and supported decision structure. [19] Maintenance is a mixture of all technical, administrative and managerial activities during the life cycle of an entity, intended to maintain or restore it to a state in which it can accomplish the required purpose [20]. Maintenance, in its constricted sense, encompasses all actions relating to the maintenance of the system and its components to a certain degree of availability and reliability and its ability to achieve a standard level of quality [3]. In other words, to optimise the specified equipment capacity, engineering decisions and related activities are required, where the ability to perform a specified function is the ability to implement a specified function within a range of performance levels that can relate to strength, speed, efficiency, safety and responsiveness [3]. The aim of maintenance activities is to plan necessary inspections, repairs and replacements and to provide management with information on the causes of defects and damage in the manufacturing sector [18].

[21] there are two types of maintenance: preventive maintenance and corrective maintenance.

- Preventive maintenance, planned to minimise the risk of an item's operating failure or deterioration, is done at a fixed period or according to a specified condition [19]. Another reason for preventive maintenance is that it strives to avoid significant breakdown and ensures that it continues by routine inspection and repair at peak performance [22]. Preventive maintenance is scheduled based on cyclic maintenance actions such as washing, local repair and local replacement to avoid degradation in advance, [23].

- Corrective maintenance comes after a breakdown when an apparent fault has been identified; then corrective maintenance, similar to repair work, is carried out [19]. As a part of corrective maintenance, because of the failure of preventive maintenance or normal wear and tear, repair and replacement components are often referred to as reactive maintenance [22].

\subsection{Maintenance Concepts}

Reliability centred maintenance (RCM) focuses on developing a systematic, inclusive maintenance strategy that takes advantage of the respective strengths of preventive, predictive and corrective maintenance strategies to optimise the reliability of equipment, reduce costs, enhance plant safety and increase productivity [24].

Total productive maintenance (TPM) is defined as a strategy projected to bring both functions (production and maintenance) together by grouping good 
working practices, teamwork and continuous improvement [25]. TPM is an innovative approach to maintenance that improves equipment effectiveness, eliminates breakdowns and promotes autonomous maintenance by operators through daily activities including the total workforce [26].

\section{Research Methodology}

The study adopted a mixed method approach to answer the research questions. Qualitative methods were the predominant source of information to respond to the research questions, the researchers interviewed relevant people from the municipality. A quantitative component in the form of a survey was used to elicit community member perceptions on quality-of-service delivery, and possibly some information about how they experience implementation of maintenance. The qualitative technique offered contributors the chance to assert their opinions, visions and clarifications on the condition of their municipal water infrastructure. As the researchers were interested in knowing the details of maintaining water infrastructure and provision of services, making use of qualitative method assisted the researchers with responses to the study's research questions. The qualitative method was utilised to understand the familiarity of the contributors about the state or problem being studied and explore the reasons for their kind of answer to the condition. The researchers' needs to go into detail about peoples' lived experiences, to elicit their explanations and analysis of their specific experiences. Hence, the researcher used structured interview question to get responses from participants. The quantitative method helped the researcher to analyse the correlation among variables. This technique permits the researcher to request all the participants' similar questions with predetermined responses, which allow objective data to be collected throughout the study. The quantitative method allows the researcher to explore and measure the situation based on statistical data such as how many people supported or didn't support certain questions or statements, and then evaluate the outcomes. The researchers make use of a questionnaire to collect data. To achieve the purpose of the study researchers conducted a survey this ensured that important variables were not overlooked.

The researchers chose convenience sampling method. Convenience sampling is a type of non-random sampling with target population members that suits the defined specifics, such as accessibility, availability and the respondent's interest to participate [27]. It is difficult to survey an entire population for a particular study due to limited time constraint. Convenience sampling makes use of people who are easily or readily available, and easily recruited, or who volunteer for sample inclusion. All the respondents who were willing to participate were invited by the researcher to complete the self-administered questionnaire and others were invited to an individual, structured interview. A total of one hundred and fifty (150) questionnaires were distributed: one hundred and thirteen (113) were completed but only hundred (100) were usable. The other thirteen (13) 
questionnaires had missing information. The target of twenty (20) people was invited for face-to-face interview questions, but only five (5) people contributed. Various charts were utilised to present the results clearly and sensibly.

\section{Results and Discussion}

The application of fishbone diagrams in Figure 3 emphasises the main categories that lead to water shortages at Limpopo Province. The information collected from the survey data reveals a water crisis including materials, equipment, measurements, people, management and environment, all reasons contributing to the water crisis due to rain scarcity. Increasing the efficiency of infrastructure will help with progression, good service provision and developmental performance results. Disruptions, or worse, breakage of services have a contradictory effect, often with serious social and economic costs. Proper planning can increase the value of money, improve a system's design quality, and even protect the environment, health and safety of the people. Planning is crucial in improving decision-making for the strategic development of infrastructure schemes. The survey

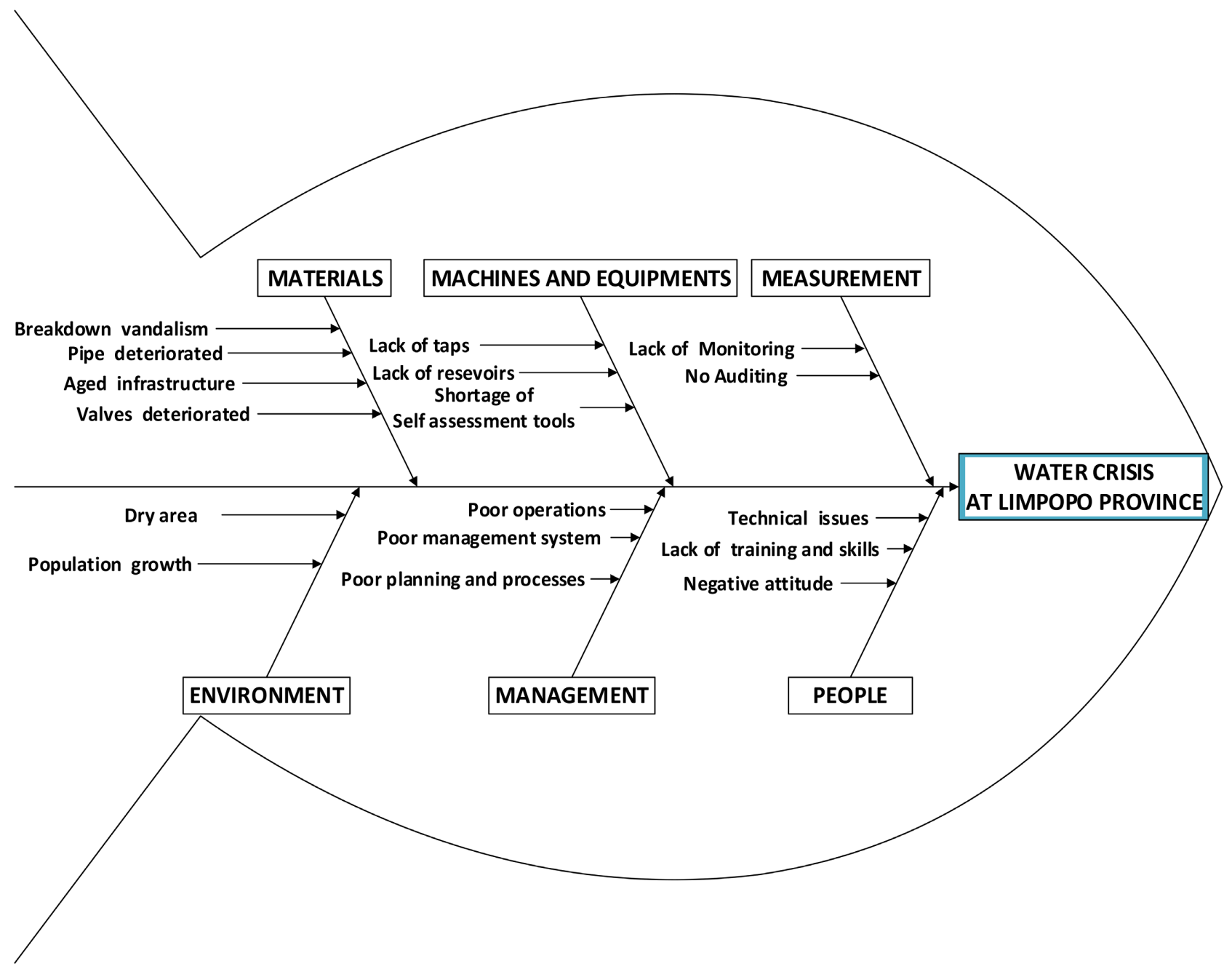

Figure 3. Cause and effect diagram. 
data analysis indicates that, indeed, water provision is a scarcity at Limpopo Province. Improved and proactive maintenance will be a calculated solution to avoid the challenges of maintenance and service delivery.

Technical audits can also assist management to ascertain where maintenance challenges lie. The municipality should create a system to observe its reliability, and act promptly whether a problem is reported or not. The municipality should budget accordingly for maintenance, both planned maintenance as well as for breakdowns and call outs. These Maintenance management strategies can be used collaboratively or independently such as: preventative maintenance; maintenance management; overall equipment efficiency; predictive maintenance; total productive maintenance; and reliability centred maintenance. Infrastructure maintenance should not be up for debate. The risks for neglecting to maintain municipality infrastructure costs the country significantly in terms of loss of revenue and economic opportunity growth. There is clear evidence that failure of infrastructure facilities has awful costs for human progress, poverty alleviation and social emancipation. Effectively functioning infrastructure is critical if the country as well as each community is to achieve any kind of economic recovery. Smooth running infrastructure programmes provide economic opportunities and act as a facilitator for generating economic growth and eventually paving the way for much needed job creation. Public properties are a foundation of a country's economic development. Preserving infrastructure in good condition is critical as all things wear with time and continuous use. Neglect will result in the deterioration of assets, with deleterious effects on the economy, in particular for high costs of reconstruction over time. The goal of maintenance is to safeguard an asset, not to upgrade it. This includes minor repairs (routine maintenance) and improvements (capital maintenance) to eliminate the cause of defects and to avoid excessive repetitions.

\section{Responses from the Survey Are Shown Below}

Based on a feedback from the participants $51 \%$ stated that it has been more than two years since the municipality performed any maintenance; $36 \%$ indicates that it has been between one to two years; $11 \%$ stated that it has been six months to 12 months; and only $2 \%$ indicated that maintenance had been performed as recently as one to five months. Responses from participants is evident that the community is not happy with the maintenance received from their municipality, refer to Figure 4.

The results on Figure 5 shows the amount of time the municipality takes to repair leaks. $67 \%$ indicated more than two months; $21 \%$ said within one month; $6 \%$ said within two weeks; $5 \%$ said within one week; and $1 \%$ said never. The results reflect a bad reputation in terms of the municipality's attendance to breakdowns. A large majority (88\%) are not satisfied with their services. The effects of repairing water leaks late impact negatively on the service delivery of water. Moreover, the municipality loses purified water that residents would have paid 


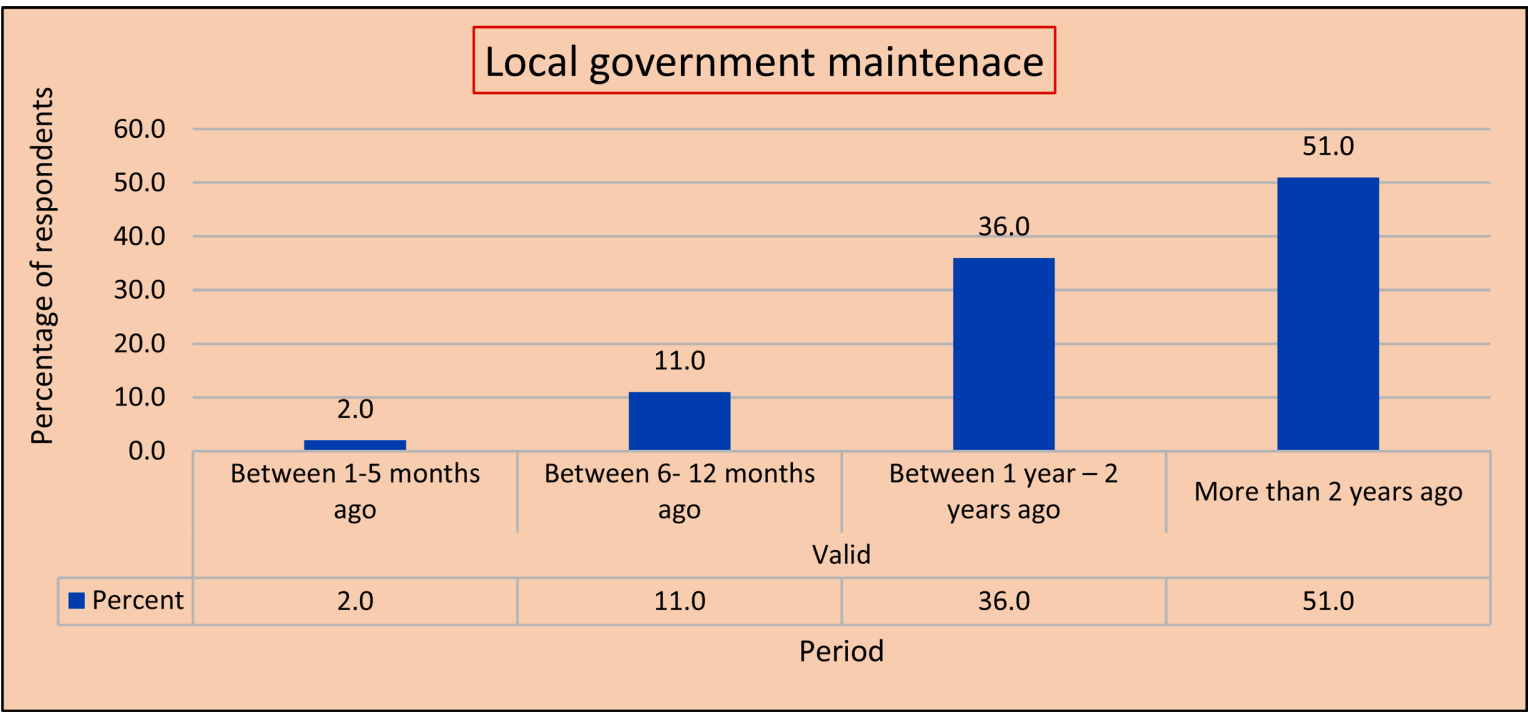

Figure 4. Local government maintenance.

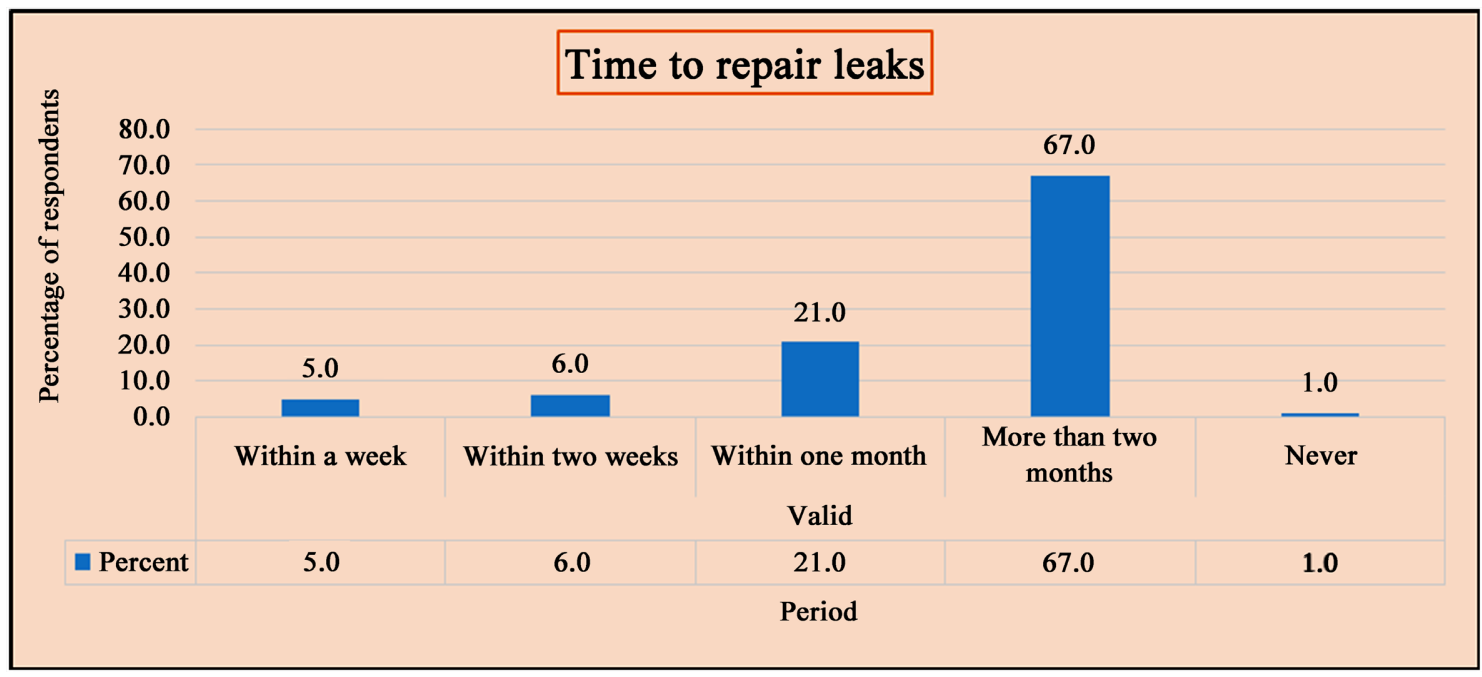

Figure 5. Time to repair leaks.

for, thus causing loss of revenue to the municipality.

Figure 6 shows the results when residents had no water. 25 participants have faced water challenges for two to three years; 19 of them for four to five years; 23 for six to seven years; and 33 have not experienced water challenges. Out of 100 participants, 77, the majority, have challenges of accessing water, while only 23 have not had water access issues for the past 6 to 7 years. It can be concluded that the majority of residents continue to experience challenges in regard to water access.

\section{Conclusions}

The study emphasised important challenges on equity and sustainability of maintenance and service provision, and recommendations were made in respect to improvements. Investigation of the responses from the communities 


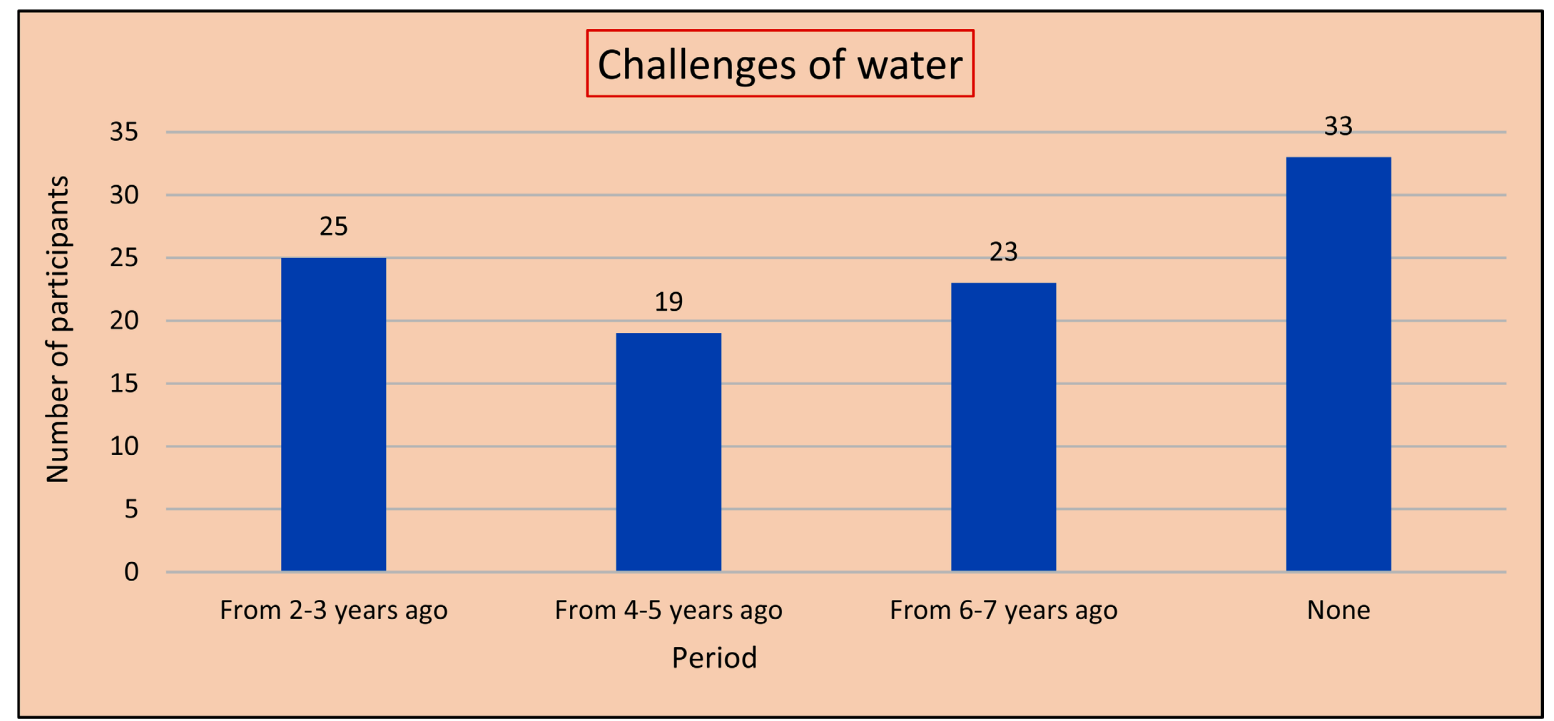

Figure 6. Challenges of water.

and employees was undertaken. The study revealed that the causes of poor maintenance and service delivery were due to improper maintenance plans, lack of communication and lack of financial availability. Rural areas should prioritise basic services. Based on the present condition of maintenance and service delivery of water, electricity, clinics, schools and roads, the municipality must endeavour to improve on the current situation. The study also shows a high rate of youth unemployment, so this matter should also be checked; the government should create more skill works and internships to keep youth busy so as to prepare and equip them for the future. Many youths have matriculated, but their employment prospects are still limited and uncertain.

The municipality should take actions based on clear policy which is premised on the rights of all people to decide their own future. The government should guarantee all South Africans access to the basic needs at a reasonable price for rural families and municipality communities. Improved and effective management methods must be adopted to alleviate the problems. An implementation of continuous management of infrastructure expansion will also assist in improving the current situation that they are facing. Benchmarking with other local municipalities will also benefit this municipality. The municipality should create a comprehensive maintenance strategy that is efficient, cost effective and safe. Strategies such as reliability centred maintenance (RCM), overall equipment effectiveness (OEE), maintenance management model, and total productive maintenance (TPM) can impact the municipality positively. Presenting developments will improve the standard and quality of maintenance and service provision. They should establish the correct blend of strategies that work best for their municipality. Planning will also help ensure that those strategies are frequently monitored and maintained for the success of infrastructure maintenance. The appropriate maintenance procedure is a vital and tactical part of supervision in every organisation, reducing failures, reducing cost and improving service deliv- 
ery.

\section{The Limitations of the Study}

- The study did not cover all the service delivery amenities. Only one municipality was studied; hence, the results cannot be generalised.

- Only ten (10) villages were selected as the case study of this research. Other villages and other municipalities couldn't be studied.

- Not all the infrastructure was covered; only the water supply was investigated in this study. Other studies could consider other elements of municipal infrastructure.

\section{Future Research}

The study only focused on water supply, yet there were many municipality service sectors that remain to be investigated. There is a need for further research to explore the maintenance of infrastructure and service delivery for other service sectors such as electricity, roads, clinics and schools. While the crisis of the quality of water supply and the maintenance are vital, this research doesn't exclude further research from being undertaken.

\section{Conflicts of Interest}

The authors declare no conflicts of interest regarding the publication of this paper.

\section{References}

[1] Constitution of the Republic of South Africa (1996).

[2] Statistics South Africa (2016) The State of Basic Service Delivery in South Africa: In-Depth Analysis of the Community Survey 2016 Data Report (No. 03-01-22 2016).

[3] Mabwe, E. (2017) Assessing Alignment of Maintenance Practices to Total Productive Maintenance Best Practice: A Case Study within a South African Conglomerate. Doctoral Dissertation, University of Witwatersrand, Johannesburg.

[4] Maharjan, D., Agüero, M., Lippitt, C. and Moreu, F. (2019) Infrastructure Stakeholders' Perspective in Development and Implementation of New Structural Health Monitoring (SHM) Technologies for Maintenance and Management of Transportation Infrastructure. MATEC Web of Conferences, 271, Article ID: 01010.

[5] Mokgobu, M.L. (2017) Challenges of the Repairs and Maintenance of Water Infrastructure in Aganang Municipality in the Province of Limpopo. Doctoral Dissertation, Durban University of Technology, Durban.

[6] Naidoo, C. and Ramphal, R.R. (2019) From Batho Pele Principles to Public Participation in Basic Services Delivery at Municipal Level in South Africa: Using Ekurhuleni Metropolitan Municipality as a Case. 13th International Business Conference, Hermanus, 22-25 September 2019, 248.

[7] Matabane, G.S. (2017) The Impact of Municipal Infrastructure Grant on Basic Service Delivery: A Case of Elias Motsoaledi Local Municipality in Limpopo Province. Doctoral Dissertation, University of Limpopo, Mankweng. 
[8] Ilie, G. and Ciocoiu, C.N. (2010) Application of Fishbone Diagram to Determine the Risk of an Event with Multiple Causes. Management Research and Practice, 2, $1-20$.

[9] Local Government: Municipal Systems Act, 32 of 2000.

[10] Ngoune, S.M.D. (2015) An Investigation into the Alleviation and Management of the Water Supply Shortage in Gauteng. Doctoral Dissertation, University of Johannesburg, Johannesburg.

[11] Mathebula, N.E., Nkuna, N.W. and Sebola, M.P. (2016) Integrated Development Plan for Improved Service Delivery: A Comparative Study of Municipalities within the Mopani District Municipality, Limpopo Province. International Journal of Business and Management Studies, 8, 70-85.

[12] Beyers, L.J.E. (2015) Service Delivery Challenges within Municipalities in the Capricorn District of Limpopo Province. Journal of Human Ecology, 50, 121-127. https://doi.org/10.1080/09709274.2015.11906866

[13] Musitha, P.M. (2018) Investigating Critical Challenges of Maintaining Road Infrastructure in the Limpopo Province: A Case of Makhado Local Municipality. Doctoral Dissertation, University of Limpopo, Mankweng.

[14] Dithebe, K., Aigbavboa, C. and Thwala, D.W. (2019) An Appraisal of Water Infrastructure Projects' Financing Challenges in South Africa. 10th Nordic Conference on Construction Economics and Organization, Tallinn, 7-8 May 2019, 103-110. https://doi.org/10.1108/S2516-285320190000002022

[15] Palmer, M.F. (2019) Exploring Alternative Methods of Service Delivery through Mobile Governance at the Swakopmund Municipality. Master's Thesis, Stellenbosch University, Stellenbosch.

[16] Presidential Health Summit (2018) Strengthening the South African Health System towards an Integrated and Unified Health System.

[17] Mangai, M.S. and De Vries, M.S. (2018) Co-Production as Deep Engagement: Improving and Sustaining Access to Clean Water in Ghana and Nigeria. International Journal of Public Sector Management, 31, 81-96. https://doi.org/10.1108/IJPSM-03-2017-0084

[18] Mkalaf, K.A. (2020) Total Productive Maintenance: A Safety Approach to Optimize the Anesthesia Device Outcomes. 2020 9th International Conference on Industrial Technology and Management (ICITM), Oxford, 11-13 February 2020, 122-126. https://doi.org/10.1109/ICITM48982.2020.9080374

[19] Rastegari, A. and Salonen, A. (2015) Strategic Maintenance Management: Formulating Maintenance Strategy. International Journal of COMADEM, 18, 5-14.

[20] Joseph, A.I. (2019) An Analytic Hierarchy Process Model Approach to Selecting a Maintenance Strategy for a New Nuclear Power Plant. Doctoral Dissertation, University of the Witwatersrand, Johannesburg.

[21] Velmurugan, R.S. and Dhingra, T. (2015) Maintenance Strategy Selection and Its Impact in Maintenance Function. International Journal of Operations \& Production Management, 35, 1622-1661. https://doi.org/10.1108/IJOPM-01-2014-0028

[22] Miya, L.U.N.G.I.S.A.N.I. and Grobbelaar, S.A.R.A. (2015) Risk-Based Maintenance of Physical Assets of Water Infrastructure: A Case Study of a Municipality. Proceedings of International Association for Management of Technology.

[23] Ruparathna, R., Hewage, K. and Sadiq, R. (2018) Multi-Period Maintenance Planning for Public Buildings: A Risk-Based Approach for Climate Conscious Operation. Journal of Cleaner Production, 170, 1338-1353. 
https://doi.org/10.1016/j.jclepro.2017.09.178

[24] Iloms, E., Ololade, O.O., Ogola, H.J. and Selvarajan, R. (2020) Investigating Industrial Effluent Impact on Municipal Wastewater Treatment Plant in Vaal, South Africa. International Journal of Environmental Research and Public Health, 17, Article ID: 1096. https://doi.org/10.3390/ijerph17031096

[25] Sahib, M.A. (2016) Studying the Requirements of (TPM) Total Productive Maintenance in Production System. Doctoral Dissertation, University of Technology, Baghdad.

[26] Madanhire, I. and Mbohwa, C. (2015) Implementing Successful Total Productive Maintenance (TPM) in a Manufacturing Plant.

[27] Wright, L. (2015) Qualitative International Management Research. Handbook for International Management Research. Blackwell, Oxford. 